\section{Phototherapy and Sonotherapy of Melanoma Cancer Cells Using Nanoparticles of Selenium-Polyethylene Glycol-Curcumin as a Dual-Mode Sensitizer}

\author{
Mohammadi S. ${ }^{1,2}$, Soratijahromi E. ${ }^{1,2}$, Dehdari Vais R. ${ }^{2}$, \\ Sattarahmady N. $3,4 *$ (0)
}

\begin{abstract}
Background: As an alternative form of cancer therapy, photothermal therapy (PTT) and sonodynamic therapy (SDT) using nanomaterials are in development. Nanomaterials can act as energy absorber as well as anti-cancer agent.

Objective: In this study, the effects of laser and ultrasound irradiation with SePEG-Cur nanoparticles were investigated on melanoma cancer.

Material and Methods: In this experimental study, nanoparticles of selenium-polyethylene glycol-curcumin (Se-PEG-Cur) were synthesized, and their UV-vis absorption, particle size, zeta potential and photothermal conversion efficiency were determined. Se-PEG-Cur was then introduced as a novel 808-nm laser light absorbing agent as well as ultrasound (US) wave for treatment of C540 (B16/F10) cancer cells. Also, ROS generation in C540 (B16/F10) cancer cells was measured upon PTT and SDT using Se-PEG-Cur.
\end{abstract}

Results: Mean size, zeta potential and photothermal conversion efficiency of SePEG-Cur were obtained as $\sim 300 \mathrm{~nm}, 42.7 \mathrm{mV}$ and $16.7 \%$, respectively. Cell viability upon irradiation of the laser light or US waves with $100 \mu \mathrm{g} \mathrm{mL}-1$ Se-PEG-Cur were decreased to 33.9 and $22.9 \%$, respectively.

Conclusion: Intracellular ROS detection indicated that dual PTT and SDT in the presence of Se-PEG-Cur induced the highest ROS production. Se-PEG-Cur was therefore introduced as an absorbing agent of both laser light and US waves for cancer treatment.

Citation: Mohammadi S, Soratijahromi E, Dehdari Vais R, Sattarahmady N. Phototherapy and Sonotherapy of Melanoma Cancer Cells Using Nanoparticles of Selenium-Polyethylene Glycol-Curcumin as a Dual-Mode Sensitizer. J Biomed Phys Eng. 2020;10(5):597-606. doi: $10.31661 /$ jbpe.v0i0.1912-1039.

\section{Keywords}

Hyperthermia; Skin Cancer; Diode Laser; Ultrasound; Nanomedicine; Reactive Oxygen Species; Cell Survival

\section{Introduction}

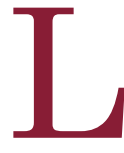
osing normal regulation and extreme cell proliferation can cause cancers. The lymphatic and circulatory systems can produce cancer cells that transferred to other parts of the body and invade tissues in living systems. They can even lead into lesions or patients death [1]. There are some limitations such as high side effects and low therapy
${ }^{1} \mathrm{MSc}$, Department of

Medical Physics, School

of Medicine, Shiraz

University of Medical Sci-

ences, Shiraz, Iran

${ }^{2} \mathrm{MSc}$, Nanomedicine

and Nanobiology Re-

search Center, Shiraz

University of Medical

Sciences, Shiraz, Iran

${ }^{3} \mathrm{PhD}$, Department of

Medical Physics, School

of Medicine, Shiraz

University of Medical Sci-

ences, Shiraz, Iran

${ }^{4} \mathrm{PhD}$, Nanomedicine

and Nanobiology Re-

search Center, Shiraz

University of Medical

Sciences, Shiraz, Iran

*Corresponding author:

N. Sattarahmady

Department of Medical

Physics, School of Medi-

cine, Shiraz University

of Medical Sciences,

Shiraz, Iran

E-mail: sattarahmady@

yahoo.com

Received: 28 December 2019

Accepted: 20 January 2020 
efficiency for common cancer therapies of chemotherapy, radiotherapy and surgery [2]. To treat cancers, two alternative phototherapy methods including photothermal therapy (PTT) and photodynamic therapy (PDT) have been developed [3-5]. Phototherapy has some advantages including spatial and temporal control, minimal invasion and low toxicity in comparison with the conventional treatments [6]. Converting near infrared (NIR) light into heat can be done during PTT as a new technology to treat cancers $[4,5,7]$. Through this route, cancer cells are killed by rising temperature, while, it has the least side effects on normal cells [8]. One of the treatment modalities in PDT is combination of a proper and suitable light wavelength with a photosensitizing agent foe selective killing the cancer cells. Formation of reactive oxygen species (ROS) such as singlet oxygen $\left({ }^{1} \mathrm{O}_{2}\right)$ or free radicals rendering necrotic and apoptotic cell death can be made by the interaction of photons with photosensitizers in the presence of oxygen molecules. ROS are correlated with deleterious effects of cancer cells including DNA fragmentation, membrane perturbation and cytoskeletal damages [9-12]. Following PDT, sonodynamic therapy (SDT) has been developed as a new noninvasive approach [13]. Beside the important advantages of SDT including less invasiveness, deeper penetration of ultrasound (US, in comparison with PDT) enables noninvasive treatment of deep-seated tumors [14]. In SDT, US activation of an agent that is called sonosensitizer usually leads to generation of ROS.

Nanotechnology has caused criteria of diagnostics and treatment to be elevated and is also considered as the best compared to the most encouraging exploration introduction for oncotherapy [15-19]. Owing to the novel bioactivities in nanostructures, inorganic nanoparticles (NPs) of metals and metal oxides have a noticeable place for biomedical applications [20-22]. Up to now, metal nanomaterials have been served as proper activator agents of laser light, US and X-ray that increase quality of cancer treatment strategies [23, 24]. One of the important nanostructures for cancer cell treatment is selenium nanoparticles with low toxicity against healthy cells $[15,25,26]$. It exhibits anticancer effect by introducing ROSmediated apoptosis in the cancerous cells [15, $25,26]$.

Curcumin that is derived from the rhizomes of turmeric [27] is a medication for treatment of different illnesses with anti-inflammatory [28], antifungal and antioxidant [28], antimicrobial [29] and anti-cancer toward various tumor cells [30-33] activities. In vitro studies showed that curcumin is more efficient against tumor cells compared to drugs such as doxorubicin and 5-fluorouracil [34]. Curcumin has a light absorption in a range of 300 to $500 \mathrm{~nm}$ enable its applications in phototherapy [35], and studies have shown that phototherapy makes an improvement in the therapeutic property of curcumin [36-40]. Nevertheless, due to its lipophilicity, poor pharmacokinetics and instability, its application is limited in medical aims. Therefore, synthesis of curcumin in the forms of nanostructures accompanied by biocompatible polymers is in progress to elevate its treatment outcome [41].

This study aims to synthesize selenium-polyethylene glycol 600-curcumin nanoparticles (Se-PEG-Cur) as a dual-mode sensitizer for phototherapy and sonotherapy using a continuous-wave laser working at $808 \mathrm{~nm}$ as a source of light and a US wave source, respectively of C540 (B16/F10) cell line. Some items, including ROS production, cell viability, and photothermal conversion efficiency were evaluated.

\section{Material and Methods}

\section{Materials}

In this experimental study, PEG600, dimethyl sulfoxide (DMSO), ascorbic acid and sodium selenite were purchased from Scharlu (Spain). 3-(4,5-dimethylthiazol-2-yl)-2,5-diphenyl tetrazoliumbromide (MTT) and 2',7'-dichlorodi- 
Selenium Nanoparticle as Photo/Sono-Sensitizer

hydrofluorescein diacetate (DCHF-DA) were prepared from Sigma (USA). Curcumin was purchased from Merck (Germany). Deionized (DI) water was used for solutions preparation.

Synthesis and characterization of Se-PEG-Cur

Sodium selenite $(500 \mathrm{mg})$ was dissolved in water $(500 \mathrm{~mL})$. Then, PEG $600(1000 \mathrm{mg})$ was added. Curcumin $(400 \mathrm{mg})$ was dissolved in acetone $(5 \mathrm{~mL})$, and added to the aforementioned solution. Ascorbic acid (12 g) was dissolved in water $(100 \mathrm{~mL})$, and dropwise added to that mixture and mixed by stirring for $24 \mathrm{~h}$. A solution with a brick red color was obtained that centrifuged at $8000 \mathrm{rpm}$ during $30 \mathrm{~min}$. Then it was washed with cold ethanol and washed multiple times with water.

UV-visible absorption spectra of the synthesized nanostructure were recoded using a Rayleigh UV2601 spectrophotometer (China). Analysis of particle size and zeta potential of the Se-PEG-Cur suspensions were performed by a SZ-100 HORIBA instrument (Japan).

\section{NIR diode laser and US instruments}

Irradiation with 808-nm light was done using a Thorlabs diode laser (USA), which has an output power of $1000 \mathrm{~mW}$. By changing the lens distance to the target, power density of laser radiation was set at $1.0 \mathrm{~W} \mathrm{~cm}^{-2}$. Time of laser light irradiation was $10 \mathrm{~min}$.

An ultrasonic instrument of Novin (Iran) was utilized for US irradiation and the US transducer was located under 96-well culture plates. A gel covered the transducer surface. US was irradiated from the bottom of plates with the parameters of output powers of 1.0 $\mathrm{W} \mathrm{cm} \mathrm{cm}^{-2}$ in a duty ratio of $100 \%$, frequency of 1 $\mathrm{MHz}$, and time of irradiation of $1 \mathrm{~min}$.

\section{Cell line preparation}

A cell line of malignant melanoma C540 (B16/F10) was prepared from Pasteur Institute (Iran). The cells were cultured in Roswell Park Memorial Institute-1640 (RPMI) medium from Gibco (USA) with 1\% antibiotic (penicillin streptomycin) from Gibco (USA) and $10 \%$ fetal bovine serum from Gibco (USA) at temperature $37^{\circ} \mathrm{C}$ in a humidified atmosphere of cell incubator, which contained $5 \% \mathrm{CO}_{2}$.

Calculation of photothermal conversion efficiency $(\eta)$ of Se-PEG-

A Se-PEG-Cur suspension $\left(100 \mu \mathrm{g} \mathrm{mL}^{-1}, 0.5\right.$ $\mathrm{mL}$ ) was exposed to NIR laser to investigate its photothermal effect in the solvent. A glass cuvette cell was utilized and real time monitoring of temperature changes upon laser irradiation were measured using a thermoprobe of Lutron (Taiwan) keeping away from the laser beam. After reaching temperature to a plateau, the laser was turned off following by permitting the cuvette to cool down to room temperature. The photothermal conversion efficiency of Se-PEG-Cur was calculated based on the method previously reported $[42,43]$.

Effects of laser and US irradiation with Se-PEG-Cur on cancer cell viability

C540 (B16/F10) cells with a density of 1.0 $\times 10^{4}$ cell well ${ }^{-1}$ were seeded into 96 -well plates during $24 \mathrm{~h}$ for cell adhesion. Then, the wells were incubated in a 5\% $\mathrm{CO}_{2}$ atmosphere at 37 ${ }^{\circ} \mathrm{C}$ and divided into the following groups:

$\mathrm{L}^{-} \mathrm{N}^{-}$or U-N*: control C540 (B16/F10) cells without any light or Se-PEG-Cur treatment

$\mathrm{L}^{-} \mathrm{N}^{+}$or $\mathrm{U}^{-} \mathrm{N}^{+}$: C540 (B16/F10) cells treated with Se-PEG-Cur of various concentrations including 5, 10, 100, 250, $500 \mu \mathrm{g} \mathrm{mL}^{-1}$ without any irradiation

$\mathrm{L}^{+} \mathrm{N}^{-}$: C540 (B16/F10) cells incubated in the culture medium for $4 \mathrm{~h}$ followed by irradiation with laser light $\left(1.0 \mathrm{~W} \mathrm{~cm}^{-2}\right)$ without any SePEG-Cur treatment. DI water of equal volume to that employed for Se-PEG-Cur dispersion in $\mathrm{N}^{+}$groups was added.

$\mathrm{L}^{+} \mathrm{N}^{+}$: C540 (B16/F10) cells treated with 100 $\mu \mathrm{g} \mathrm{mL} \mathrm{mL}^{-1}$ of Se-PEG-Cur for $4 \mathrm{~h}$ followed by irradiation with laser light $\left(1.0 \mathrm{~W} \mathrm{~cm}^{-2}\right)$

$\mathrm{U}^{+} \mathrm{N}^{-}$: C540 (B16/F10) cells incubated in the 
culture medium for $4 \mathrm{~h}$ followed by irradiation with US wave $\left(1.0 \mathrm{~W} \mathrm{~cm}^{-2}\right)$ without any SePEG-Cur treatment. DI water of equal volume to that employed for Se-PEG-Cur dispersion in $\mathrm{N}^{+}$groups was added.

$\mathrm{U}^{+} \mathrm{N}^{+}$: C540 (B16/F10) cells treated with $100 \mu \mathrm{g} \mathrm{mL}^{-1}$ of Se-PEG-Cur for $4 \mathrm{~h}$ followed by irradiation with US wave $\left(1.0 \mathrm{~W} \mathrm{~cm}^{-2}\right)$

$\mathrm{L}^{+} \mathrm{U}^{+} \mathrm{N}^{-}$: C540 (B16/F10) cells incubated in the culture medium for $4 \mathrm{~h}$ followed by irradiation with laser light $\left(1.0 \mathrm{~W} \mathrm{~cm}^{-2}\right)$, and then immediately irradiated with US $\left(1.0 \mathrm{~W} \mathrm{~cm}^{-2}\right)$ without any Se-PEG-Cur treatment. DI water of equal volume to that employed for Se-PEGCur dispersion in $\mathrm{N}^{+}$groups was added.

$\mathrm{L}^{+} \mathrm{U}^{+} \mathrm{N}^{+}$: C540 (B16/F10) cells treated with $100 \mu \mathrm{g} \mathrm{mL}^{-1}$ of Se-PEG-Cur for $4 \mathrm{~h}$ followed by irradiation with laser light $\left(1.0 \mathrm{~W} \mathrm{~cm}^{-2}\right)$, and then immediately irradiated with US (1.0 $\mathrm{W} \mathrm{cm}^{-2}$ )

The time of incubation for various groups of the cells was 24 or 72 hours at $37{ }^{\circ} \mathrm{C}$ and $5 \% \mathrm{CO}_{2}$. It should be noted that for $24 \mathrm{~h}$ of incubation, the cells were incubated with Se-PEG-Cur for $24 \mathrm{~h}$ following by washing and performing the MTT assay, as described below. However, for $72 \mathrm{~h}$ of incubation, the cells were incubated with Se-PEG-Cur for 24 $\mathrm{h}$, then they washed off from Se-PEG-Cur, a fresh culture medium was added, and incubation was continued for another $48 \mathrm{~h}$. Finally, following by washing the cells, the MTT assay was performed as described below. The cell viability was assayed by the MTT method. The cell medium was replaced with $100 \mu \mathrm{L}$ of 0.5 $\mathrm{mg} \mathrm{mL} \mathrm{m}^{-1}$ MTT, which was incubated at $37^{\circ} \mathrm{C}$ for $4 \mathrm{~h}$ in dark and dissolved in phosphate buffer saline (PBS). Then, the plates were centrifuged for $15 \mathrm{~min}$ to remove the supernatants. Next, $100 \mu \mathrm{L}$ of DMSO was added in order to dissolve the MTT formazan crystals. After centrifuging for $10 \mathrm{~min}$, the supernatant was eliminated from every well, and the optical density (OD) was measured at $570 \mathrm{~nm}$ using a microplate reader from Biotek (USA). Finally, the viability of the cells was stated as the ratio of the $570 \mathrm{~nm}$ absorbance of the treated cells and control ones.

\section{Detection of intracellular ROS}

The DCF assay was applied to measure intracellular ROS level. Briefly, C540 (B16/F10) cells at a density of $1.0 \times 10^{4}$ cell well $^{-1}$ were seeded in 96-well plates. Various cell groups (Section 2.6) were treated after $24 \mathrm{~h}$. After incubation with $100 \mu \mathrm{g} \mathrm{mL}^{-1}$ of Se-PEG-Cur for $3.5 \mathrm{~h}, 100 \mu \mathrm{L}$ of a fresh DCHF-DA solution $\left(50 \mu \mathrm{mol} \mathrm{L}^{-1}\right)$ was added to these treated cells. After laser or US irradiation, the cells were incubated for $30 \mathrm{~min}$ followed by washing (3 times) with PBS to remove the extracellular DCF. Then, $100 \mu \mathrm{L}$ of a lysis buffer containing $150 \mathrm{mmol} \mathrm{L}^{-1} \mathrm{NaCl}+0.1 \%$ Triton X-100+50 mmol L ${ }^{-1}$ Tris- $\mathrm{HCl}$ at $\mathrm{pH}=8.0$ was added to the wells. The intensity of fluorescence emission at $520 \mathrm{~nm}$ was then measured upon excitation at $485 \mathrm{~nm}$ after $30 \mathrm{~min}$ by amicroplate reader of Biotek (USA).

\section{Statistical analysis}

For each sample, at least three parallel experiments were performed. p-values less than 0.05 were considered statistically significant through the t-test.

\section{Results}

An absorption spectrum of Se-PEG-Cur is shown in Figure 1A. To determine the SePEG-Cur size, dynamic light scattering was performed, and the results are shown in Figure 1B. The mean particle size of Se-PEGCur was obtained as $\sim 300 \mathrm{~nm}$ with a uniform dispersion index (PDI 0.1). Zeta potential of Se-PEG-Cur was also measured to be -42.7 $\mathrm{mV}$, as shown in Figure 1C. This value of zeta potential led to a high stability of Se-PEG-Cur without formation of aggregates [44].

To investigate the photothermal conversion efficiency $(\eta)$ of Se-PEG-Cur, a rise in temperature was measured for a $100 \mu \mathrm{g} \mathrm{mL}^{-1} \mathrm{Se}-$ PEG-Cur suspension with 808 -nm irradiation at a power density of $1.0 \mathrm{~W} \mathrm{~cm}^{-2}$. The results 


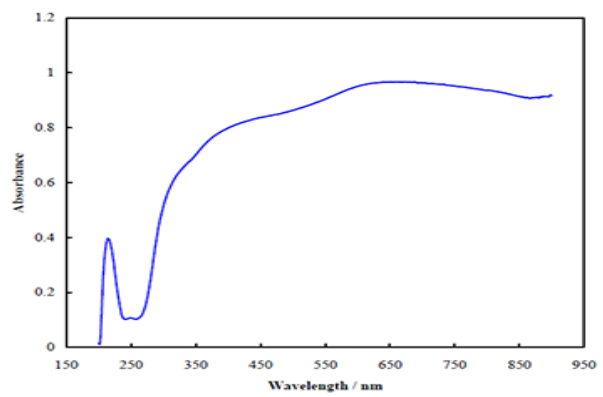

A

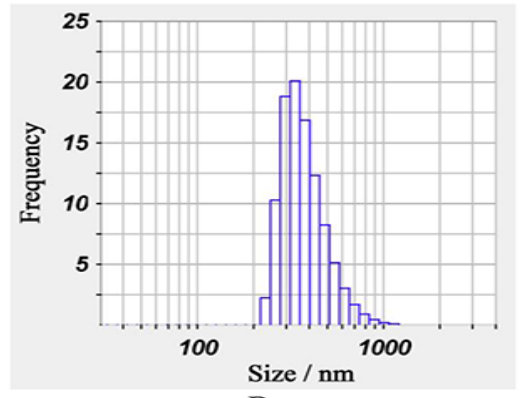

B

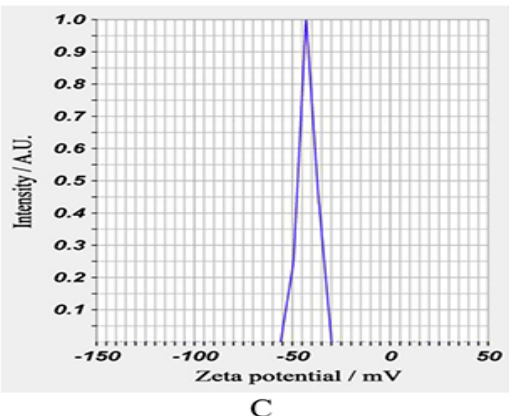

C

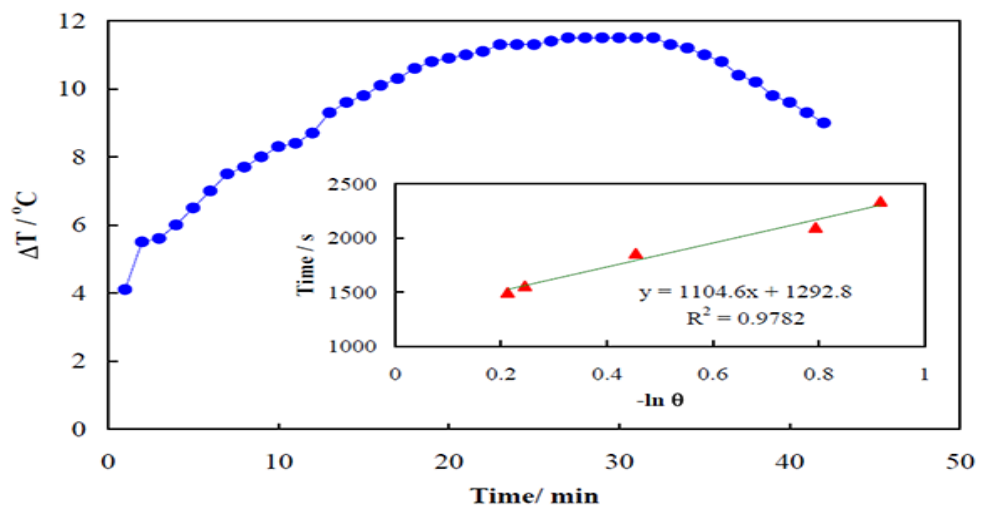

D

Figure 1: UV-vis spectra recorded for the selenium-polyethylene glycol-curcumin (Se-PEG-Cur) (A), size distribution (B), zeta potential (C), and temperature changes of Se-PEG-Cur of $100 \mu \mathrm{g}$ $\mathrm{mL}^{-1}$ in water upon laser irradiation (to reach $\mathrm{T}_{\max }$ ) subsequent by laser light shutting off (cooling). Inset: Dependency of $-\ln \theta$ on $t$

showed a temperature increment of $11.5{ }^{\circ} \mathrm{C}$ for the Se-PEG-Cur suspension, as shown in Figure 1D, while, the control had a small temperature increment. $\eta$ was calculated according to the equation:

$\eta=\left[\mathrm{hs}\left(\mathrm{T}_{\mathrm{MAX}}-\mathrm{T}_{\text {SURR }}\right)-\mathrm{Q}_{\mathrm{DIS}}\right] /\left[\mathrm{I}\left(1-10^{-\mathrm{A}}\right)(1)\right.$

Where h, s, I and A are the coefficient of heat transfer, the container surface area, power density of laser (equal to $1.0 \mathrm{~W} \mathrm{~cm}^{-2}$ ) and absorbance at wavelength of $808 \mathrm{~nm}$, respectively, and $\mathrm{T}_{\max }$ and $\mathrm{T}_{\text {surr }}$ are the equilibrium and ambient temperatures, respectively. $\mathrm{Q}_{\mathrm{DIS}}$ is the heat dispersed from light, is absorbed by the cuvette, and was independently measured to be $7.0 \mathrm{~mW}$ as the cuvette contained pure water (without Se-PEG-Curt NPs). The product of hs is:

$$
\text { hs }=\mathrm{mC} / \tau
$$

Where $\mathrm{m}$ and $\mathrm{C}$ are the mass and specific heat of pure water, and $\tau$ is slope of dependency of cooling time on $-\ln \theta$, and $\theta$ is:

$$
\theta=\left(\mathrm{T}-\mathrm{T}_{\text {SURR }}\right) /\left(\mathrm{T}_{\text {MAX }}-\mathrm{T}_{\text {SURR }}\right)
$$


Dependency of cooling time on $-\ln \theta$ is shown in the inset of Figure 1D, and considering a value of 0.93 for $\mathrm{A}_{808}$ for the Se-PEG-Cur, $\eta$ for Se-PEG-Cur was obtained as $16.7 \%$.

To evaluate the efficacy of Se-PEG-Cur upon PTT, SDT and PTT/SDT on the C540 (B16/F10) cells, the cell viability was assessed by the MTT assay. First, in vitro cytotoxicity of various concentrations $\left(5-500 \mu \mathrm{g} \mathrm{mL}^{-1}\right)$ of Se-PEG-Cur without any US or laser radiation was measured, and the viability percentages of the cells treated with Se-PEG-Cur after 24 or $72 \mathrm{~h}$ of incubation (in comparison with untreated ones) are shown in Figure 2A, B. Figure $2 \mathrm{~A}$ indicated upon increasing Se-PEG-Cur

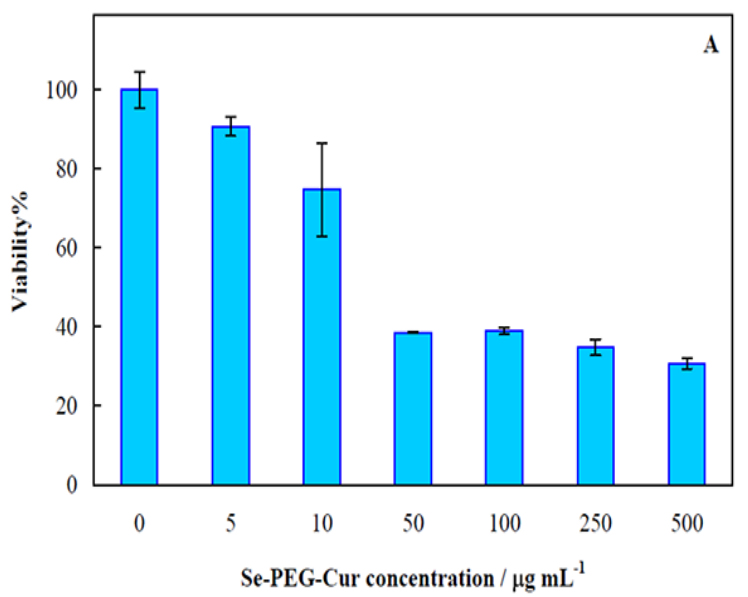

concentration, the cell viability decreased after $24 \mathrm{~h}$ incubation, and reached $30 \%$ in the presence of $500 \mu \mathrm{g} \mathrm{mL}^{-1}$ Se-PEG-Cur. Figure 2B also indicated that the cell viability decreased upon increasing in the Se-PEG-Cur concentration after $72 \mathrm{~h}$ incubation, and the viability reached $22 \%$ in the presence of $500 \mu \mathrm{g} \mathrm{mL}^{-}$ ${ }^{1}$ Se-PEG-Cur.

In following, PTT and SDT effects of SePEG-Cur on viability of C540 (B16/F10) cells were investigated. Figure $2 \mathrm{C}$ shows viabilities of different groups of cell including $\mathrm{L}^{-} \mathrm{N}^{-}$, $\mathrm{U}^{-} \mathrm{N}^{-}, \mathrm{L}^{+} \mathrm{N}^{-}, \mathrm{U}^{+} \mathrm{N}^{-}, \mathrm{L}^{-} \mathrm{N}^{+}, \mathrm{U}^{-} \mathrm{N}^{+}, \mathrm{L}^{+} \mathrm{N}^{+}, \mathrm{U}^{+} \mathrm{N}^{+}$and $\mathrm{L}^{+} \mathrm{U}^{+} \mathrm{N}^{+}$after $72 \mathrm{~h}$ of incubation.

Figure 3 shows the fluorescence intensity
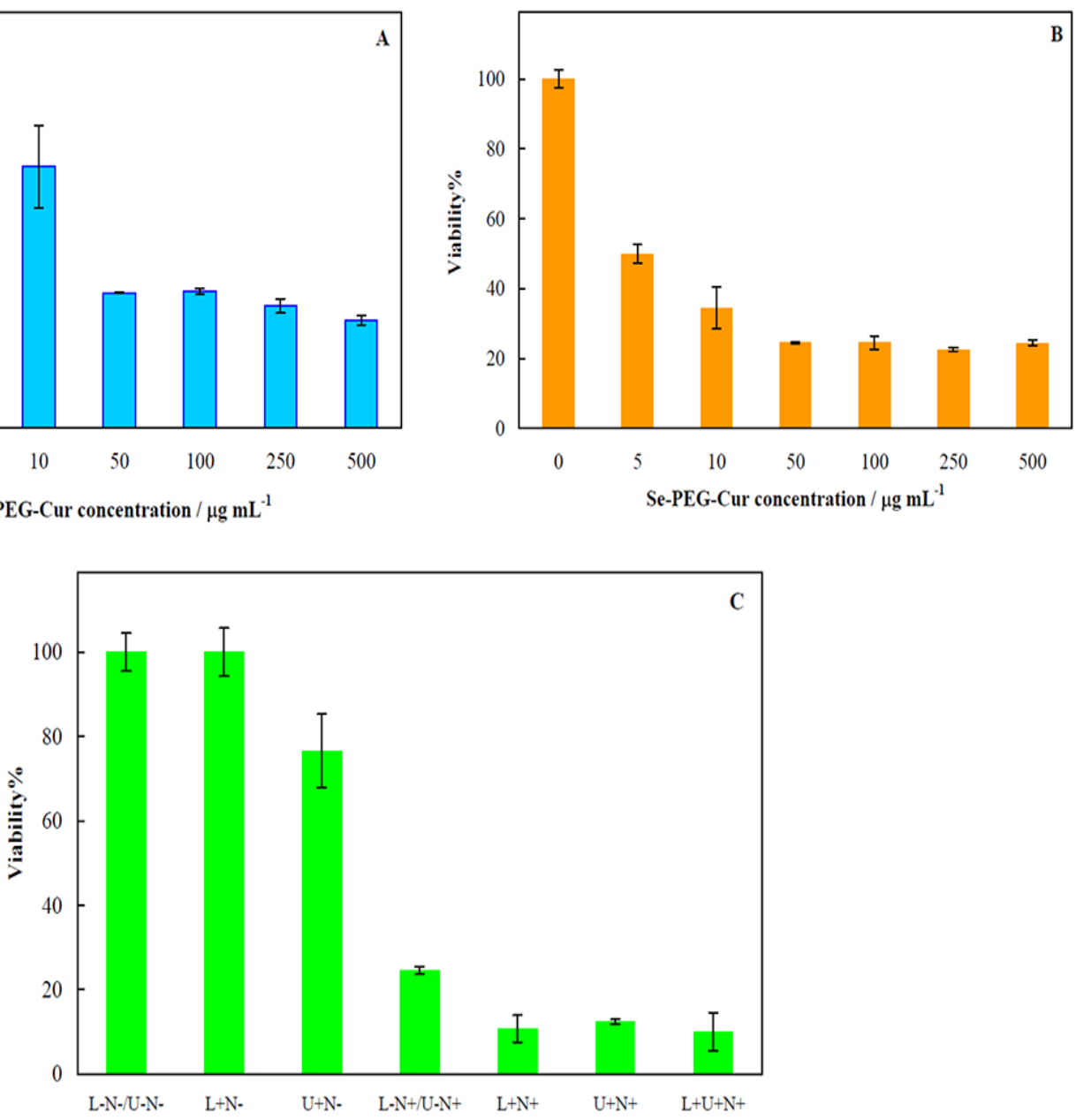

Figure 2: Viability of C540 (B16/F10) cell after exposure to selenium-polyethylene glycol-curcumin (Se-PEG-Cur), 5-500 $\mathrm{gg} \mathrm{mL}^{-1}$ after $24 \mathrm{~h} \mathrm{(A)}$, after $72 \mathrm{~h} \mathrm{(B)} \mathrm{incubation} \mathrm{time,} \mathrm{and} \mathrm{Viability} \mathrm{of}$ C540 (B16/F10) cell after exposure to Se-PEG-Cur (100 $\left.\mathrm{g} \mathrm{mL}^{-1}\right)$ and radiation with laser and/or ultrasound (US) (C). 


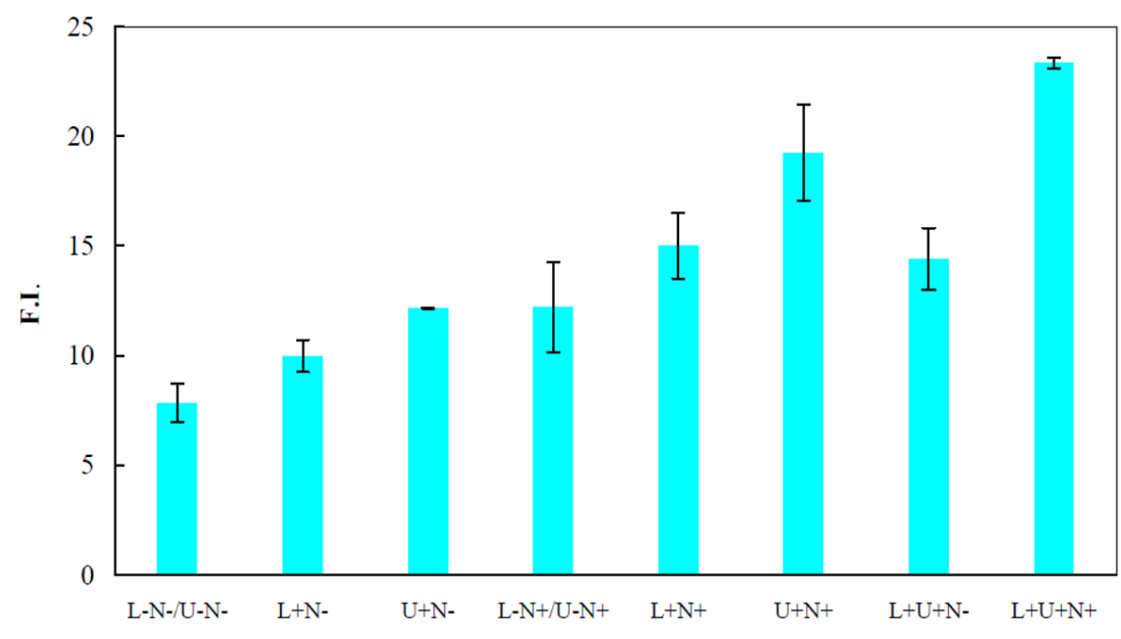

Figure 3: Fluorescence intensity (FI) of dichlorofluorescein (DCF) in C540 (B16/F10) cell after exposure to selenium-polyethylene glycol-curcumin (Se-PEG-Cur), $100 \mu \mathrm{g} \mathrm{mL}^{-1}$ and radiation with laser and/or ultrasound (US) .

(FI) of generated DCF that was an indicator of the intracellualar level of ROS formation in different groups of C540 (B16/F10) cells.

\section{Discussion}

Recently, melanoma incidence has nearly reached epidemic proportion. By current clinical tools, it is not possible to cure late-stage melanoma [45]. For treatment of cancer, it is necessary to replace conventional therapeutic strategies with non-invasive methods. These novel methods aim to early cancer diagnosis, reduce side effects and preserve normal tissues $[46,47]$. An absorption peak of Se-PEG-Cur at about $212 \mathrm{~nm}$ can be related to PEG, and the broad peaks at longer wavelengths are due to overlapping the selenium and curcumin of SePEG-Cur. The ability of Se-PEG-Cur to absorb 808-nm light is witnessed from the spectrum. The value of zeta potential led to a high stability of Se-PEG-Cur without formation of aggregates [44]. Also, $\eta$ value for Se-PEG-Cur was obtained as $16.7 \%$.

The viability results (Figures $2 \mathrm{~A}$ and $\mathrm{B}$ ) showed the toxicity behavior of Se-PEG-Cur. Statistical analysis of the results indicated a noticeable influence of Se-PEG-Cur at concentrations more than $10 \mu \mathrm{g} \mathrm{mL}^{-1}$ on the $\mathrm{C} 540$
(B16/F10) cells viability, compared to the untreated cells. However, the cytotoxicity of Se-PEG-Cur at high concentrations of 50 to $500 \mu \mathrm{g} \mathrm{mL}^{-1}$ was almost the same (with no significant differences) maybe due to an opposite behavior of selenium and curcumin parts of Se-PEG-Cur; the former would generated ROS and the later would act as an antioxidant. This hypothesis needs more investigations. Anyway, $100 \mu \mathrm{g} \mathrm{mL} \mathrm{m}^{-1}$ Se-PEG-Cur and $72 \mathrm{~h}$ of incubation were selected for further investigations. It should also be added that the results obtained for $72 \mathrm{~h}$ of incubation indicated that although the cells were washed off from SePEG-Cur after $24 \mathrm{~h}$, continuing the incubation without Se-PEG-Cur represented decrement in the cell viability. This pointed out that SePEG-Cur penetrated inside the cells, and its effect was prolonged to the end of incubation time.

The viability results in Figure 2C, revealed that irradiation of laser in $\mathrm{L}^{+} \mathrm{N}^{-}$led to a $7 \%$ decrement in the C540 (B16/F10) cell viability, compared to $\mathrm{L}^{-} \mathrm{N}^{-}$with no significant difference. The viability of cells in $\mathrm{L}^{+} \mathrm{N}^{+}$had a noticeable decrease $(\mathrm{p}<0.05)$, in comparison with the cell viability of $\mathrm{L}^{-} \mathrm{N}^{-}, \mathrm{L}^{+} \mathrm{N}^{-}$and $\mathrm{L}^{-} \mathrm{N}^{+}$. The difference between the cell viabilities of $\mathrm{L}^{-} \mathrm{N}^{+}$ 
and $\mathrm{L}^{+} \mathrm{N}^{+}$was about $14 \%$. Thus, laser irradiation made an effective photothermal treatment with the assistant of Se-PEG-Cur as a photosensitizer. On the other hand, the results indicated that US irradiation in $\mathrm{U}^{+} \mathrm{N}^{-}$reduced the C540 (B16/F10) cell viability about $23 \%$ in comparison with the control cells $\left(\mathrm{U}^{-} \mathrm{N}^{-}\right)$. Besides, the cell viability in $\mathrm{U}^{+} \mathrm{N}^{+}$noticeably decreased $(\mathrm{p}<0.05)$, in comparison with the cell viability of $\mathrm{U}^{-} \mathrm{N}^{-}, \mathrm{U}^{+} \mathrm{N}^{-}$and $\mathrm{U}^{-} \mathrm{N}^{+}$. There was a $12 \%$ difference between the cell viabilities in $\mathrm{U}^{-} \mathrm{N}^{+}$and $\mathrm{U}^{+} \mathrm{N}^{+}$. In order to evaluate the combined effect of laser and US irradiation in the presence of Se-PEG-Cur, the cell viability of $\mathrm{L}^{+} \mathrm{U}^{+} \mathrm{N}^{+}$was evaluated. It was found that there was no significant decrease in the cell viability of $\mathrm{L}^{+} \mathrm{U}^{+} \mathrm{N}^{+}(\mathrm{p}>0.05)$, compared to the cell viabilities of $\mathrm{U}^{+} \mathrm{N}^{+}$and $\mathrm{L}^{+} \mathrm{N}^{+}$. Thus, to attain a significant efficiency from dual radiation of laser and US in the presence of Se-PEG-Cur, repeated treatments by laser or US would be useful.

The results in Figure 3 showed that ROS production in different groups had the order of (with significant differences) $\mathrm{L}^{-} \mathrm{N}^{-}$or $\mathrm{U}^{-}$ $\mathrm{N}^{-}<\mathrm{L}^{+} \mathrm{N}^{-}<\mathrm{U}^{+} \mathrm{N}^{-}=\mathrm{L}^{-} \mathrm{N}^{+}$or $\mathrm{U}^{-} \mathrm{N}^{+}<\mathrm{L}^{+} \mathrm{N}^{+}<\mathrm{L}^{+} \mathrm{U}^{+} \mathrm{N}^{-}$ $<\mathrm{U}^{+} \mathrm{N}^{+}<\mathrm{L}^{+} \mathrm{U}^{+} \mathrm{N}^{+}$. Although laser radiation alone induced a very low ROS level compare to untreated cells, its radiation in the presence of Se-PEG-Cur produced ROS upon the PTT process. On the other hand, either US irradiation or Se-PEG-Cur alone induced ROS production in C540 (B16/F10) cells. US radiation in the presence of Se-PEG-Cur exacerbated ROS production along with the SDT process. The ROS generation upon dual treatment of laser and US exposure in the absence of SePEG-Cur was lower than that generated upon dual treatment in the presence of Se-PEG-Cur; dual PTT and SDT induced the highest ROS production, and this was arose from the sensitizing role of Se-PEG-Cur.

\section{Conclusion}

We synthesized and characterized Se-PEGCur as an efficient NIR and US absorbing agent, and therefore as a sensitizer for both PTT and SDT to kill melanoma cancer cells via thermal effects and ROS generation, respectively. More investigations are needed to explore the role of the sensitizer components (Se, PEG and Cur) to identify the ROS generating species as well as antioxidant active component(s). In vivo applicability of SePEG-Cur would be another subject of further investigations.

\section{Acknowledgment}

This paper has been extracted from S. Mohammadi's MSc thesis supported by the Research Council of Shiraz University of Medical Sciences (21051).

\section{Conflict of Interest}

None

\section{References}

1. Tachibana K, Feril LB, Ikeda-Dantsuji Y. Sonodynamic therapy. Ultrasonics. 2008;48(4):253-9. doi: 10.1016/j.ultras.2008.02.003.

2. Kievit FM, Zhang M. Surface engineering of iron oxide nanoparticles for targeted cancer therapy. Acc Chem Res. 2011;44(10):853-62. doi: 10.1021/ ar2000277.

3. Shibu ES, Hamada M, Murase N, Biju V. Nanomaterials formulations for photothermal and photodynamic therapy of cancer. J Photoch Photobio C. 2013;15:53-72. doi: 10.1016/j.jphotochemrev.2012.09.004.

4. Gorgizadeh M, Azarpira N, Dehdari Veis R, Sattarahmady N. Repression of melanoma tumor in vitro and in vivo by photothermal effect of carbon xerogel nanoparticles. Colloid Surface B. 2019;176: 449-55. doi: 10.1016/j.colsurfb.2019.01.032. PubMed PMID: 30682617.

5. Sattarahmady N, Rezaie-Yazdi M, Tondro GH, Akbari N. Bactericidal laser ablation of carbon dots: An in vitro study on wild-type and antibiotic-resistant Staphylococcus aureus. J Photoch Photobio B. 2017;166: 323-32. doi: 10.1016/j.jphotobiol.2016.12.006. PubMed PMID: 28024283.

6. Cheng L, Wang C, Feng L, Yang K, Liu Z. Functional nanomaterials for phototherapies of cancer. Chem Rev. 2014;114(21):10869-939. doi: 10.1021/cr400532z.

7. Lal S, Clare SE, Halas NJ. Nanoshell-enabled pho- 
Selenium Nanoparticle as Photo/Sono-Sensitizer

tothermal cancer therapy: impending clinical impact. Acc Chem Res. 2008;41(12):1842-51. doi: 10.1021/ar800150g. PubMed PMID: 19053240.

8. Chen J, Ning C, Zhou Z, Yu P, Zhu Y, Tan G, et al. Nanomaterials as photothermal therapeutic agents. Prog Mater Sci. 2019;99:1-26. doi: 10.1016/j. pmatsci.2018.07.005.

9. Bergamini CM, Gambetti S, Dondi A, Cervellati C. Oxygen, reactive oxygen species and tissue damage. Curr Pharm Des. 2004;10(14):1611-26. doi: $10.2174 / 1381612043384664$.

10. Jin H, Zhong X, Wang Z, Huang X, Ye H, Ma S, et al. Sonodynamic effects of hematoporphyrin monomethyl ether on CNE-2 cells detected by atomic force microscopy. J Cell Biochem. 2011;112(1):169-78. doi: 10.1002/jcb.22912. PubMed PMID: 21053362.

11. Wan G-Y, Liu Y, Chen B-W, Liu Y-Y, Wang Y-S, Zhang N. Recent advances of sonodynamic therapy in cancer treatment. Cancer Biol Med. 2016;13(3):325. doi: 10.20892/j.issn.20953941.2016.0068.

12. Gorgizadeh M, Azarpira N, Lotfi M, Daneshvar F, Salehi F, Sattarahmady N, Sonodynamic cancer therapy by a nickel ferrite/carbon nanocomposite on melanoma tumor: In vitro and in vivo studies. Photodiagn Photodyn. 2019;27:27-33. doi: 10.1016/j.pdpdt.2019.05.023.

13. Dolmans DE, Fukumura D, Jain RK. Photodynamic therapy for cancer. Nat Rev Cancer. 2003;3(5):380 doi: 10.1038/nrc1071.

14. Qian X, Zheng Y, Chen Y. Micro/NanoparticleAugmented Sonodynamic Therapy (SDT): Breaking the Depth Shallow of Photoactivation. Adv Mater. 2016;28(37):8097-129. doi: 10.1002/ adma.201602012.

15. Huang $Y$, He L, Liu W, Fan C, Zheng W, Wong $Y-S$, et al. Selective cellular uptake and induction of apoptosis of cancer-targeted selenium nanoparticles. Biomaterials. 2013;34(29):7106-16. doi: 10.1016/j.biomaterials.2013.04.067.

16. Yazdani Z, Yadegari H, Heli H. A molecularly imprinted electrochemical nanobiosensor for prostate specific antigen determination. Anal Biochem 2019;566:116-25. doi: 10.1016/j.ab.2018.11.020.

17. Rahi A, Sattarahmady N, Heli H. Zepto-molar electrochemical detection of Brucella genome based on gold nanoribbons covered by gold nanoblooms. Sci Rep. 2015;5:18060. doi: 10.1038/srep18060. PMCID: PMC4677304.

18. Ajdari MR, Tondro GH, Sattarahmady N, Parsa A, Heli H. Phytosynthesis of silver nanoparticles using Myrtus communis L. leaf extract and inves- tigation of bactericidal activity. J Electron Mater. 2017;46:6930-5. doi: 10.1007/s11664-017-57842.

19. Rahi A, Karimian K, Heli H. Nanostructured materials in electroanalysis of pharmaceuticals. Anal Biochem. 2016;497:39-47. doi: 10.1016/j. ab.2015.12.018.

20. Khurana A, Tekula S, Saifi MA, Venkatesh P, Godugu C. Therapeutic applications of selenium nanoparticles. Biomed Pharmacother. 2019;111:802-12. doi: 10.1016/j.biopha.2018.12.146.

21. Heli H, Pishahang J, Barzegar Amiri H. Synthesis of hexagonal CoAl-layered double hydroxide nanoshales/carbon nanotubes composite for the non-enzymatic detection of hydrogen peroxide. J Electroanal Chem. 2016;768:134-44. doi: 10.1016/j.jelechem.2016.01.042.

22. Heli H, Majdi S, Jabbari A, Sattarahmady N, Moosavi-Movahedi AA. Electrooxidation of dextromethorphan on a carbon nanotube-carbon microparticle-ionic liquid composite: Applied to determination in pharmaceutical forms. J Solid State Electr. 2010;14:1515-23. doi: 10.1007/s10008009-0979-y.

23. Pogue BW, Wilson BC. Optical and $x$-ray technology synergies enabling diagnostic and therapeutic applications in medicine. $J$ Biomed Opt. 2018;23:121610. doi: 10.1117/1. JB0.23.12.121610.

24. Canavese G, Ancona A, Racca L, Canta M, Dumontel B, Barbaresco F, Limongi T, Cauda V. Nanoparticle-assisted ultrasound: A special focus on sonodynamic therapyagainst cancer. Chem Eng J. 2018;340:155-72. doi: 10.1016/j.cej.2018.01.060.

25. Yu B, Li X, Zheng W, Feng Y, Wong Y-S, Chen T. pH-responsive cancer-targeted selenium nanoparticles: a transformable drug carrier with enhanced theranostic effects. J Mater Chem $B$. 2014;2(33):5409-18. doi: 10.1039/C4TB00399C.

26. Ramasamy T, Ruttala HB, Sundaramoorthy P, Poudel BK, Youn YS, Ku SK, et al. Multimodal selenium nanoshell-capped Au@mSiO2 nanoplatform for NIR-responsive chemo-photothermal therapy against metastatic breast cancer. NPG Asia Mater. 2018;10(4):197. doi: 10.1038/s41427-018-00345.

27. Liu J, Chen S, Lv L, Song L, Guo S, Huang S. Recent progress in studying curcumin and its nano-preparations for cancer therapy. Curr Pharm Design. 2013;19(11):1974-93. doi: 10.2174/138161213805289327.

28. Martins CVB, Da Silva DL, Neres ATM, Magalhaes 
TFF, Watanabe GA, Modolo LV, Sabino AA, De Fatima A, De Resende MA. Curcumin as a promising antifungal of clinical interest. $J$ Antimicrob Chemother. 2009;63:337-39. doi: 10.1093/jac/ dkn488.

29. Ribeiro APD, Pavarina AC, Dovigo LN, Brunetti IL, Bagnato VS, Vergani CE, De Souza Costa CA. Phototoxic effect of curcumin on methicillin-resistant Staphylococcus aureus and L929 fibroblasts. Lasers Med Sci. 2013;28:391-98. doi: 10.1007/ s10103-012-1064-9.

30. Kuttan R, Bhanumathy P, Nirmala K, George MC. Potential anticancer activity of turmeric (Curcuma longa). Cancer Lett. 1985;29:197-202. doi: 10.1016/0304-3835(85)90159-4.

31. Choudhuri T, Pal S, Agwarwal ML, Das T, Sa G. Curcumin induces apoptosis in human breast cancer cells through p53-dependent Bax induction. FEBS Lett. 2002;512:334-40. doi: 10.1016/S00145793(02)02292-5.

32. Javvadi P, Segan AT, Tuttle SW, Koumenis C. The chemopreventive agent curcumin is a potent radiosensitizer of human cervical tumor cells via increased reactive oxygen species production and overactivation of the mitogen-activated protein kinase pathway. Mol Pharmacol. 2008;73:1491-501. doi: 10.1124/mol.107.043554.

33. Liu HL, Chen Y, Cui GH, Zhou JF. Curcumin, a potent antitumor reagent, is a novel histone deacetylase inhibitor regulating BNHL cell line Raji proliferation. Acta Pharmacol Sin. 2005;26:603-09. doi: 10.1111/j.1745-7254.2005.00081.x.

34. Lopez-Lazaro M. Anticancer and carcinogenic properties of curcumin: considerations for its clinical development as a cancer chemopreventive and chemotherapeutic agent. Mol Nutr Food Res. 2008;52:S103-27. doi: 10.1002/mnfr.200700238.

35. Dujic J, Kippenberger S, Ramirez-Bosca A, DiazAlperi J, Bereiter-Hahn J, Kaufmann R, Bernd A, Hofmann M. Curcumin in combination with visible light inhibits tumor growth in a xenograft tumor model. Int J Cancer. 2009;124:1422-28. doi: 10.1002/ijc.23997.

36. Zeng X, Leung A, Xia X, Yu H, Bai D, Xiang J, et al. Effect of; blue light radiation on curcumininduced cell death of breast cancer cells. Laser Phys. 2010;20(6):1500-3. doi: 10.1134/ S1054660X10110332.

37. Dovigo LN, Pavarina AC, Ribeiro APD, Brunetti IL, Costa CADS, Jacomassi DP, et al. Investigation of the photodynamic effects of curcumin against Candida albicans. Photochem Photobiol. 2011;87(4):895-903. doi: 10.1111/j.1751- 1097.2011.00937.x.

38. Andrade MC, Ribeiro APD, Dovigo LN, Brunetti IL, Giampaolo ET, Bagnato VS, et al. Effect of different pre-irradiation times on curcumin-mediated photodynamic therapy against planktonic cultures and biofilms of Candida spp. Arch Oral Biol. 2013;58(2):200-10. doi: 10.1016/j.archoralbio.2012.10.011.

39. Rahimi-Moghaddam F, Azarpira N, Sattarahmady $N$. Evaluation of a nanocomposite of PEG-curcumin-gold nanoparticles as a near-infrared photothermal agent: An in vitro and animal model investigation. Laser Med Sci. 2018;33:1769-79. doi: 10.1007/s10103-018-2538-1.

40. Rahimi-Moghaddam F, Sattarahmady N, Azarpira N. Gold-Curcumin Nanostructure in Photothermal Therapy on Breast Cancer Cell Line: 650 and $808 \mathrm{~nm}$ Diode Lasers as Light Sources. J Biomed Phys Eng. 2018;9(4);473-82. doi: 10.31661/jbpe. v0i0.906. PMID: 31531301. PMCID: PMC6709349

41. Sindhu K, Rajaram A, Sreeram K, Rajaram R. Curcumin conjugated gold nanoparticle synthesis and its biocompatibility. Rsc Adv. 2014;4:1808-18. doi: 10.1039/C3RA45345F.

42. Hessel CM, Pattani VP, Rasch M, Panthani MG, Koo B, Tunnell JW, et al. Copper selenide nanocrystals for photothermal therapy. Nano Lett. 2011;11(6):2560-6. doi: 10.1021/nl201400z.

43. Tian $Q$, Jiang F, Zou R, Liu Q, Chen Z, Zhu M, et al. Hydrophilic Cu9S5 nanocrystals: a photothermal agent with a $25.7 \%$ heat conversion efficiency for photothermal ablation of cancer cells in vivo. ACS Nano. 2011;5(12):9761-71. doi: 10.1021/ nn203293t.

44. Kokila K, Elavarasan N, Sujatha V. Diospyros montana leaf extract-mediated synthesis of selenium nanoparticles and their biological applications. New J Chem. 2017;41(15):7481-90. doi: 10.1039/ C7NJ01124E.

45. Song C, Park H, Lee C, Griffin R. Implications of increased tumor blood flow and oxygenation caused by mild temperature hyperthermia in tumor treatment. Int J Hyperther. 2005;21(8):761-7. doi: $10.1080 / 02656730500204487$.

46. Alexis F, Rhee JW, Richie JP, et al. New frontiers in nanotechnology for cancer treatment. Urologic Oncology. 2008;26(1):74-85. doi: 10.1016/j. urolonc.2007.03.017.

47. Ji Z, Lin G, Lu Q, Meng L, Shen X, Dong L, et al. Targeted therapy of SMMC-7721 liver cancer invitro and invivo with carbon nanotubes based drug delivery system. J Colloid Interf Sci. 2012;365(1):1439. doi: 10.1016/j.jcis.2011.09.013. 